\title{
Obstructive sleep apnea co-morbidity in patients with fibromyalgia: a single-center retrospective analysis and literature review
}

This article was published in the following Dove Press journal:

Open Access Rheumatology: Research and Reviews

\author{
Edwin S Meresh' \\ Hewa Artin ${ }^{2}$ \\ Cara Joyce ${ }^{3}$ \\ Steven Birch ${ }^{4}$ \\ David Daniels' \\ Jack H Owens' \\ Alvaro J La Rosa' \\ Murali S Rao' \\ Angelos Halaris' \\ 'Department of Psychiatry, Loyola \\ University Medical Center, Maywood, IL \\ 60I53, USA; ${ }^{2}$ Loyola Stritch School of \\ Medicine, Maywood, IL 60I53, USA; \\ ${ }^{3}$ Biostatistics Core, Clinical Research \\ Office, Loyola University Medical Center, \\ Maywood, IL 60I53, USA; ${ }^{4}$ Informatics and \\ Systems Development, Loyola University \\ Medical Center, Maywood, IL 60I53, USA
}

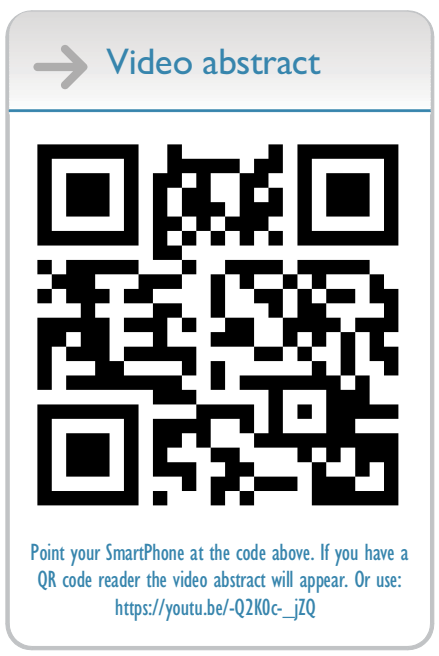

Correspondence: Edwin S Meresh

Department of Psychiatry, Loyola University Medical Center, 2160 S. First Ave, Bldg 105,

Rm 1940, Maywood, IL 60I53, USA

Tel + I 7082163274

Email Emeresh@lumc.edu
Background: Fibromyalgia (FM) is a chronic medical condition characterized by widespread pain, sleep disturbance, and cognitive dysfunction. Sleep disorders are thought to play a prominent role in the etiology and symptomatic management of FM, specifically obstructive sleep apnea (OSA). In order to provide collaborative care, we need a better understanding of any overlapping presentation of FM and OSA. We conducted a site-wide review of patients from 2012-2016 to identify FM patients diagnosed with OSA.

Methods: Charts were reviewed in patients aged 18 and above from 2012-2016 using ICD codes from a clinical data repository. Intersection of patients with a diagnosis of FM and OSA in clinics of psychiatry, sleep, rheumatology, and other outpatient clinics was compared. Polysomnography order patterns for FM patients were investigated.

Results: Co-morbidity was highest in the sleep clinic $(85.8 \%)$ compared to psychiatry $(42.0 \%)$, rheumatology $(18.7 \%)$, and other outpatient clinics $(3.6 \%)(p<0.001)$. In the rheumatology and other outpatient clinics, $93.5 \%$ and $96 \%$ of patients respectively, had no polysomnography ordered. Pairwise comparison of co-morbidity in clinics: sleep vs psychiatry, sleep vs rheumatology, sleep vs other clinics, psychiatry vs rheumatology, psychiatry vs other clinics, and rheumatology vs other clinics were statistically significant after applying a Sidak adjustment to the $p$-values (all $p<0.001$ ).

Conclusion: Our analysis suggests that there could be a correlation between FM and OSA, and referral to sleep studies is recommended in the management of patients with FM. The varying prevalence of FM patients with co-morbid OSA in sleep clinics when compared to other outpatient clinics suggests a discrepancy in the identification of FM patients with OSA. When properly screened, OSA co-morbidity has the potential to be higher in other outpatient clinics. Keywords: fibromyalgia, obstructive sleep apnea, co-morbidity, sleep, rheumatology, psychiatry

\section{Introduction}

Fibromyalgia (FM) is a medical condition associated with chronic pain and characteristic areas of heightened tenderness to pressure ${ }^{1}$ and is associated with suffering, ${ }^{2}$ economic costs, and lost productivity. ${ }^{3-6}$ Epidemiological data suggest that the disease varies in prevalence from $2 \%-8 \%$ and that it occurs more commonly in females. ${ }^{7}$ The disease is occasionally seen alongside co-morbid functional disorders such as interstitial cystitis and irritable bowel disorder. ${ }^{8}$ Individuals with FM are also more likely to have psychiatric disorders, including depression, anxiety, obsessive compulsive disorders, and post-traumatic stress disorders. ${ }^{7}$ While the exact etiology of FM is unclear, the disease is thought to be due to central nervous system dysfunction leading to an increased sensitivity to pain. ${ }^{7-9}$ 
There are known genetic and environmental factors that correlate with the disease and individuals are more likely to develop the disease if a first-degree family member is affected. ${ }^{10}$ Environmental factors are also associated with the disease and include physical trauma, infections, and psychological stress. ${ }^{7}$ Treatment of FM is typically geared toward cognitive behavioral therapy as well as improving sleep patterns, and promoting increased activity and exercise. Pharmacotherapy with duloxetine or pregabalin may also be an option, and opioids, while controversial, are occasionally used in treating FM. ${ }^{11}$

Other symptoms commonly associated with FM are: fatigue, sleep disturbance, memory problems, ${ }^{7}$ and nonrestorative sleep ${ }^{7}$ suggesting a relationship between obstructive sleep apnea (OSA) and FM. ${ }^{12,13}$ OSA is common and often goes unrecognized, leading to medical and economic consequences. ${ }^{14-16}$

Sleep abnormalities could lead to increased pain perception. ${ }^{17,18}$ Sleep plays a prominent role in both the etiology and treatment of FM. One commonly observed sleep disturbance in patients with FM is alpha-wave intrusions during deep sleep. ${ }^{12}$ Some studies have also suggested a correlation between sleep-disordered breathing and FM. ${ }^{13}$ It has been established that women with FM had sleepdisordered breathing. ${ }^{13}$ FM may be a marker for occult sleep apnea in males. ${ }^{19}$ This is a particularly noteworthy correlation to explore since care for patients with FM is often scattered due to co-morbidities. Because of psychiatric co-morbidities of both OSA and FM, these patients are also commonly under the care of psychiatry and pain clinics and end up being on medications including benzodiazepines and opioids. Combination of opioids and benzodiazepines could lead to worse outcomes in OSA and patients could become dependent on opioid pain medications. ${ }^{20,21}$

The brain's mechanism of pain modulation involves complex pathways. ${ }^{22}$ Little is known about the neural circuitry underlying this phenomenon. Loss of 4 hours of rapid eye movement sleep is associated with hyperalgesia. ${ }^{23}$ A unique electroencephalography (EEG) finding has been observed in patients with OSA and FM. In this study by Rosenfeld et al, OSA co-morbidity was reported to be $45 \%$. This study also identified low delta/alpha ratio during nonrapid eye movement sleep. ${ }^{24} \mathrm{~A}$ case series study has also demonstrated that treatment of underlying sleep-disordered breathing can improve subjective pain symptoms in patients with $\mathrm{FM}^{25}$

If OSA is the primary sleep abnormality in FM, could a safer treatment like continuous positive airway pressure
(CPAP) represent a better option than benzodiazepines? If OSA is contributing to increased pain perception, treating the underlying sleep apnea and related problems could decrease pain perception, and eventually lead to decrease in opioid use. As mentioned, studies are emerging associating FM and OSA, and much remains to be learned about polysomnographic findings. It is important to know the percentage of patients with diagnosis of OSA and FM combined. This could lead to a better understanding of this overlapping presentation, leading to appropriate treatment and avoiding unnecessary polypharmacy. Our study sought to further investigate the co-morbidity of FM with OSA.

\section{Methods}

Institutional Review Board (IRB) for the Protection of Human Subjects, Loyola University Chicago, Health Science Division, approved the study as expedited. Patient consent to review their medical records was not required by the IRB, the study was of minimal risk and identifiers were confidential. The study is in compliance with the Declaration of Helsinki. We sought to identify patients aged 18 and above with a diagnosis of FM and OSA across all outpatient clinics including psychiatry, sleep, and rheumatology between 2012 and 2016. Our institution's large-scale clinical data repository was queried using super-computer assistance to perform a site-wide analysis of outpatients from the Loyola University Chicago health system from 2012-2016. Data were obtained from the electronic medical records and inclusion criteria were applied using ICD-9 and ICD-10 codes. Diagnoses of FM were determined using ICD-9 code 729.1 and ICD-10 codes M79.1 and M79.7. OSA diagnoses were identified by using ICD-9 code 327.23 and ICD-10 code G47.33. ${ }^{26}$ Polysomnography (PSG) order patterns for FM patients in rheumatology and other outpatient clinics were investigated by looking for sleep study orders. Patients considered to have FM were diagnosed by their primary care physician based on a clinical evaluation, physical exam, and by ruling out conditions with similar symptoms. Patients considered to have OSA were diagnosed after a sleep study (PSG test results).

\section{Inclusion criteria}

1. Patients diagnosed with FM;

2. patients diagnosed with OSA;

3. number of patients diagnosed with FM carrying diagnosis of OSA. Table 1 shows identifying OSA co-morbidity in FM patients. 
Table I Identifying obstructive sleep apnea (OSA) co-morbidity in fibromyalgia (FM) patients

\begin{tabular}{|c|c|c|c|}
\hline $\begin{array}{l}\text { Psychiatry clinic } \\
(n=2,393)\end{array}$ & $\begin{array}{l}\text { Sleep clinic } \\
(n=6,975)\end{array}$ & $\begin{array}{l}\text { Rheumatology clinic } \\
(n=8,607)\end{array}$ & Other clinics $(n=380,666)$ \\
\hline Included & Included & Included & Included \\
\hline FM & FM & FM & FM \\
\hline$n=364(15.2 \%)$ & $\mathrm{n}=1,205(17.2 \%)$ & $n=2,505(29.1 \%)$ & $n=15,106(3.9 \%)$ \\
\hline OSA & OSA & OSA & OSA patients \\
\hline$n=393(16.4 \%)$ & $n=6,011 \quad(86.1 \%)$ & $\mathrm{n}=1,003(1 \mathrm{I} .6 \%)$ & $\mathrm{n}=7,501 \quad(1.9 \%)$ \\
\hline FM with OSA & FM with OSA & FM with OSA & FM with OSA \\
\hline$n=153(42.0 \%)$ & $\mathrm{n}=1035(85.8 \%)$ & $n=470(18.7 \%)$ & $n=552(3.6 \%)$ \\
\hline Excluded & Excluded & Excluded & Excluded \\
\hline No OSA or $F M=1,789$ & No OSA or $\mathrm{FM}=794$ & No OSA or $F M=5,569$ & No OSA or $F M=358,611$ \\
\hline
\end{tabular}

\section{Statistical methods}

Patients were categorized according to their treatment clinic and compared across psychiatry, sleep, rheumatology, and other Loyola outpatient clinics, and the statistical significance of the association of clinic with co-morbid OSA and FM was assessed with a chi-squared test. Pairwise comparisons of co-morbidity by clinic were assessed with a Sidak adjustment applied to $p$-values for multiple comparisons.

\section{Results}

Table 2 shows the number of patients with FM and OSA and combined FM and OSA in psychiatry, sleep, rheumatology, and other outpatient clinics. The highest proportion of FM patients were present in rheumatology clinic $(2,505 / 8,607)$ followed by sleep $(1,205 / 6,975)$, psychiatry $(364 / 2,393)$, and other clinics $(15,106 / 380,666)$. FM patients were mostly female $(14,833 / 19,180)$, OSA patients were mostly male $(8,583 / 14,908)$.

The highest rate of co-morbidity in FM was in sleep clinics $(85.8 \%)$ and the contributory factor is naturally the presence of OSA patients. Also, FM patients referred to sleep clinics had a sleep study done. But, data from the rheumatology and remaining outpatient clinics demonstrate that patients with FM were not regularly referred for PSG. In rheumatology clinics, of the 2,035 FM patients without OSA, PSG was ordered in 131 patients (6.4\%) and no PSG was ordered in 1,904 patients (93.5\%). Eighty-five of the 131 patients for whom PSG was ordered (64\%) did not complete their study. In other outpatient clinics, of the 14,554 FM patients without OSA, PSG was ordered for 585 patients $(4.0 \%)$ and no PSG was ordered for 13,969 patients (96\%). Four hundred and sixteen of the 585 patients for whom PSG was ordered (71\%) did not complete their study.

Our analysis showed that the co-morbidity of sleep apnea and FM was highest in sleep clinics (85.8\%) compared to psychiatry $(42.0 \%)$, rheumatology $(18.7 \%)$, and the remainder of outpatient clinics $(3.6 \%)(p<0.001$ for all comparisons) (Figure 1).

\section{Discussion}

Data regarding the prevalence of OSA in FM patients are emerging. This chart review shows there could be an association between FM and OSA. When looking at the correlation and association between FM and OSA, there could be a difference based on methodology. The difference in the rates of co-morbid FM with OSA between our center's outpatient clinics, specifically the increased comorbidity identified in the sleep clinic compared to the psychiatry, rheumatology, and other outpatient clinics suggests a potential discrepancy in the identification of FM patients with OSA.

In other clinics except psychiatry, sleep, and rheumatology, prevalence of FM with OSA co-morbidity was only $3.6 \%$. When psychiatry, sleep, and rheumatology clinics' FM cohort was added to the other clinics, FM with OSA co-morbidity increased to $11.9 \%$, pointing out 
Table 2 Number of patients with fibromyalgia (FM) and obstructive sleep apnea (OSA) and combined FM and OSA in psychiatry, sleep, rheumatology, and all other outpatient clinics

\begin{tabular}{|c|c|c|c|}
\hline & \multicolumn{3}{|c|}{ Psychiatry clinic $(n=2,393)$} \\
\hline & $\begin{array}{l}F M \\
n=364(15.2 \%)\end{array}$ & $\begin{array}{l}\text { OSA } \\
n=393(16.4 \%)\end{array}$ & $\begin{array}{l}\text { Both FM and OSA } \\
n=153(42.0 \%)\end{array}$ \\
\hline Age, mean, SD & $57.36,15.43$ & $56.19,13.43$ & $53.95,13.22$ \\
\hline \multirow[t]{3}{*}{ Female, n (\%) } & $276(75.8)$ & $226(57.5)$ & II 3 (73.8) \\
\hline & \multicolumn{3}{|c|}{ Sleep clinic $(n=6,975)$} \\
\hline & $\begin{array}{l}F M \\
n=I, 205(17.2 \%)\end{array}$ & $\begin{array}{l}\text { OSA } \\
n=6,011(86.1 \%)\end{array}$ & $\begin{array}{l}\text { Both FM and OSA } \\
n=1,035(85.8 \%)\end{array}$ \\
\hline Age, mean, SD & $53.27,13.13$ & $52.32,13.37$ & $53.01,12.62$ \\
\hline \multirow[t]{3}{*}{ Female, n (\%) } & 859 (7I.2) & $2,775(46.1)$ & $718(69.3)$ \\
\hline & \multicolumn{3}{|c|}{ Rheumatology clinic $(n=8,607)$} \\
\hline & $\begin{array}{l}F M \\
n=2,505 \text { (29.1\%) }\end{array}$ & $\begin{array}{l}\text { OSA } \\
n=1,003(11.6 \%)\end{array}$ & $\begin{array}{l}\text { Both FM and OSA } \\
n=470(18.7 \%)\end{array}$ \\
\hline Age, mean, SD & $53.02,15$ & $55.12,12.55$ & $54.64,11.87$ \\
\hline \multirow[t]{3}{*}{ Female, n (\%) } & $2,124(84.7)$ & $649(64.7)$ & $366(77.8)$ \\
\hline & \multicolumn{3}{|c|}{ All other clinics excluding psychiatry, sleep, and rheumatology clinics $(n=380,666)$} \\
\hline & $\begin{array}{l}F M \\
n=15,106(3.9 \%)\end{array}$ & $\begin{array}{l}\text { OSA } \\
n=7,501 \quad(1.9 \%)\end{array}$ & $\begin{array}{l}\text { Both FM and OSA } \\
n=552(3.6 \%)\end{array}$ \\
\hline Age, mean, SD & $52.8,17.08$ & $58.3,13.86$ & $58.28,13.69$ \\
\hline \multirow[t]{3}{*}{ Female, n (\%) } & II,574 (76.6) & $2,675(35.6)$ & $345(62.5)$ \\
\hline & \multicolumn{3}{|c|}{ Other clinics including psychiatry, sleep, and rheumatology $(n=404,048)$} \\
\hline & $\begin{array}{l}F M \\
n=20,304(5.2 \%)\end{array}$ & $\begin{array}{l}\text { OSA } \\
n=17,603(4.3 \%)\end{array}$ & $\begin{array}{l}\text { Both FM and OSA } \\
n=2,429(11.9 \%)\end{array}$ \\
\hline Age, mean, SD & $53.3,16.55$ & $55.2,13.82$ & $55.18,12.99$ \\
\hline Female, n (\%) & $15,66 \mid(77.1)$ & $7,292(41.4)$ & $\mathrm{I}, 632(67.1)$ \\
\hline
\end{tabular}

the clustering of FM with OSA in psychiatry, sleep, and rheumatology clinics with the highest in sleep clinics $(85.8 \%)$. FM with its overlap with rheumatology could explain the high amount of FM patients in that clinic (29.1\%). Similarly, $42.0 \%$ of patients with FM with OSA co-morbidity in psychiatry clinics could be explained by psychosomatic aspects of FM and the psychiatric comorbidity of OSA.

Most patients, once they are registered at a sleep clinic, will undergo a sleep study. Our data suggest that in the rheumatology and other outpatient clinics, 93.5\% and 96\% of FM patients respectively were not referred for PSG. We were not able to identify, in our retrospective study, the reason for this low referral rate. A prospective survey could address this. Given that $96 \%$ of FM patients in outpatient clinics were not referred for PSG, referral to specialists is needed when treating patients with FM. What could explain this likely correlation? What could be the connecting factor? Is FM leading to sleep apnea or sleep apnea leading to FM? One possible way to look into this is to establish which group of patients was identified firstselection of patients based on their OSA status and then look for FM criteria vs selection where FM patients were identified first and then tested for OSA. In Alvarez Lario et al's study, ${ }^{27}$ the authors wanted to determine whether sleep disorders can cause FM. They studied 30 patients 


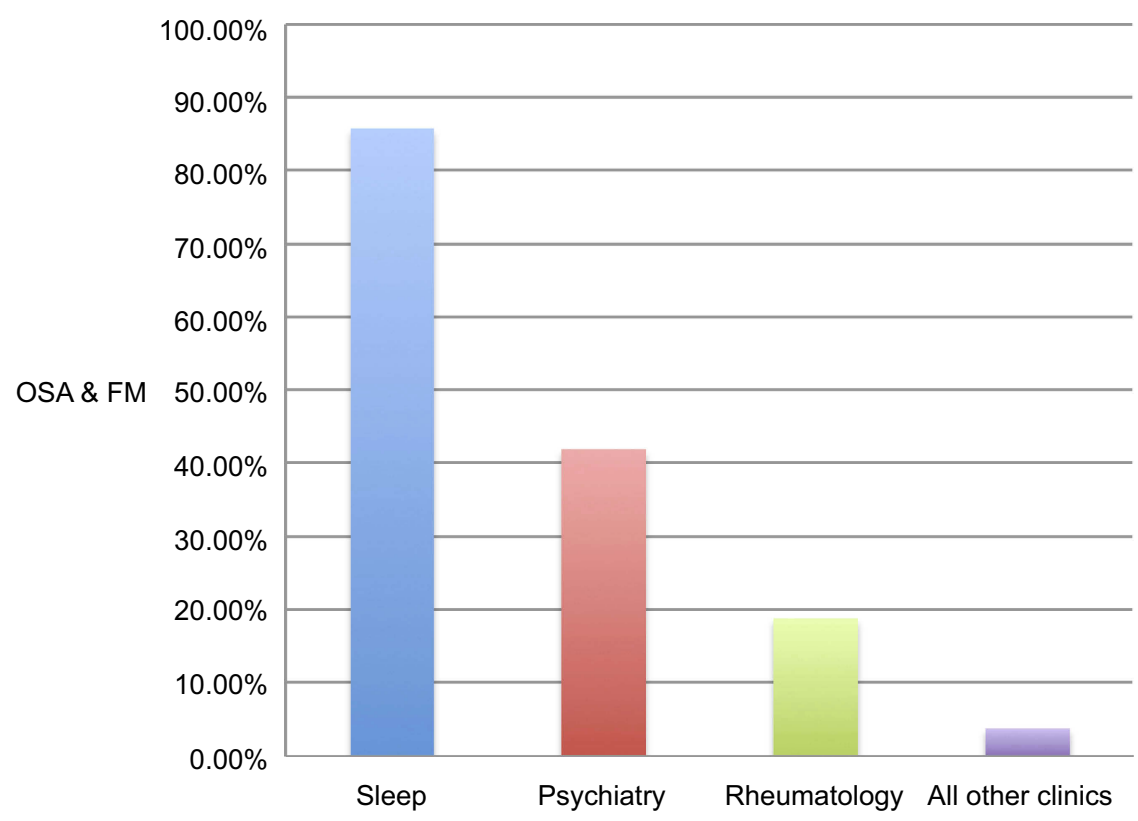

Figure I Percentage of patients with fibromyalgia and obstructive sleep apnea in psychiatry, sleep, rheumatology, and all other outpatient clinics. Abbreviations: FM, fibromyalgia; OSA, obstructive sleep apnea.

diagnosed with sleep apnea and only one patient met criteria for $\mathrm{FM}^{27}$ If a cohort of OSA patients is chosen and evaluated for $\mathrm{FM}$, the rate is around $15 \%$, as in this study. ${ }^{25}$ In Marvisi et al's study, the authors studied 900 consecutive OSA subjects and a total of $135(15 \%)$ patients fulfilled criteria for FM. ${ }^{25}$ Similarly, in a study of FM occurrence in OSA where OSA patients were screened for FM, there was absence of correlation. ${ }^{28}$ In our study (Table 2), in sleep clinics, 1,205 (17.2\%) of the 6,975 patients had FM. However, of the 1,205 FM patients, 1,035 had OSA (85.8\%). This indicates the possibility that ifthere is a causal mechanism at all, it is likely that FM is leading to OSA rather than OSA leading to FM. On the other hand, when a cohort of FM patients was evaluated for OSA, the rate was much higher. ${ }^{13}$ In this study, when they identified FM patients and then investigated for co-morbid OSA, co-morbidity was higher (83\%) had apnea-hypopnea index greater than 15, explaining a stronger correlation between FM and OSA. It is possible that variables like obesity in FM could be leading to OSA. ${ }^{29}$ Research is needed in this area.

There are other explanations for poor sleep among FM patients aside from OSA. American College of Rheumatology included symptoms such as waking unrefreshed, fatigue, tiredness, and insomnia in the 2010 diagnostic criteria for FM. ${ }^{30}$ Patients complain of feeling tired and unrefreshed. ${ }^{31}$ Wakefulness, unrefreshing sleep, and diffused myalgia have been studied and are associated with the alpha EEG pattern. ${ }^{32}$ Correct diagnosis of underlying sleep disturbance in FM patients is important because if the underlying sleep abnormality also includes OSA, combining benzodiazepine with opioid medication could lead to adverse health outcomes including more fatigue. $^{33,34}$ There are early reports of beneficial effect of CPAP in FM. ${ }^{25}$ Studies are needed to see if medications could be helpful. Sodium oxybate has been looked at for FM and has been shown to improve pain and fatigue in FM patients. ${ }^{35}$ Sleep disorders like OSA can have tremendous medical and economic consequences for individual patients and for society. Cardiac and vascular morbidity in OSA may include systemic hypertension, cardiac arrhythmias, pulmonary hypertension, cor-pulmonale, left ventricular dysfunction, stroke, and sudden death. ${ }^{14}$ Our analysis suggests that there may be a correlation between FM and OSA, and collaborative care and referral to sleep studies are recommended in the management of patients with FM. In reviewing the literature we sought to explore the relationship between FM and OSA. FM patients should be screened for OSA and referred for PSG, as needed. This review has limitations. This study was a retrospective chart review where the diagnosis of FM was based on the patients' diagnosis list as evaluated and entered by the primary medical provider. This analysis was unique at the patient-level of that particular clinic. The clinic was chosen first and the patient group in that clinic was analyzed before studying the next clinic. We identified co-morbidities for each clinic. All 
sleep apnea patients are referred to a sleep clinic to undergo a sleep study. To correctly identify OSA co-morbidity among FM patients across all clinics, a prospective study is needed. FM patients with no existing documented history of OSA should be identified from all clinics before the patient is referred for a sleep study. Patients should then be referred for a sleep study to rule out OSA.

\section{Conclusion}

FM is a potentially disabling condition that can affect an individual's ability to function at home or at work. The disease is poorly understood, although there are certain known risk factors and associated conditions that are worthy targets of investigation. Our study focused on investigating sleep-disordered breathing, specifically OSA, as a potential co-morbid medical condition in individuals with FM. Among various clinics, highest co-morbidity was identified at sleep clinics. The variance in prevalence of FM patients with concomitant OSA in the sleep clinic when compared to other outpatient clinics suggests a discrepancy in the identification of $\mathrm{FM}$ patients with $\mathrm{OSA}^{36}$ When properly screened, the co-morbidity of FM with OSA has the potential to be higher in other outpatient clinics. This suggests the need for collaborative care and referral to specialists for PSG when managing patients with FM. Prospective multi-center studies, to confirm our findings, are also necessary in future collaborations. There might be an association between OSA and FM. FM patients should be evaluated for OSA and studies are needed to see if CPAP could be helpful.

\section{Disclosure}

The authors report no conflicts of interest in this work.

\section{References}

1. sSteinweg DL, Dallas AP, Rea WS. Fibromyalgia: unspeakable suffering, a prevalence study of alexithymia. Psychosomatics. 2011;52 (3):255-262. doi:10.1016/j.psym.2010.12.022

2. Chandran A, Schaefer C, Ryan K, Baik R, McNett M, Zlateva G. The comparative economic burden of mild, moderate, and severe fibromyalgia: results from a retrospective chart review and cross-sectional survey of working-age U.S. adults. J Manag Care Pharm. 2012;18 (6):415-426. doi:10.18553/jmcp.2012.18.6.415

3. Kim SK, Kim SH, Lee CK, et al. Effect of fibromyalgia syndrome on the health related quality of life and economic burden in Korea. Rheumatology (Oxford). 2013;52(2):311-320. doi:10.1093/rheumatology/kes 255

4. Robinson RL, Kroenke K, Mease P, et al. Burden of illness and treatment patterns for patients with fibromyalgia. Pain Med. 2012;13 (10):1366-1376. doi:10.1111/j.1526-4637.2012.01475.x
5. Schaefer C, Mann R, Masters ET, et al. The comparative burden of chronic widespread pain and fibromyalgia in the United States. Pain Pract. 2016;16(5):565-579. doi:10.1111/papr.12302

6. Masters ET, Mardekian J, Emir B, Clair A, Kuhn M, Silverman SL. Electronic medical record data to identify variables associated with a fibromyalgia diagnosis: importance of health care resource utilizations. J Pain Res. 2015;5(8):131-138. doi:10.2147/JPR

7. Clauw DJ. Fibromyalgia. A clinical review. JAMA. 2014;311 (15):1547-1555. doi:10.1001/jama.2014.3266

8. Gur A, Oktayoglu P. Central nervous system abnormalities in fibromyalgia and chronic fatigue syndrome: new concepts in treatment. Curr Pharm Des. 2008;14(13):1274-1294.

9. Hudson JI, Pope HG. The concept of affective spectrum disorder: relationship to fibromyalgia and other syndromes of chronic fatigue and chronic muscle pain. Baillieres Clin Rheumatol. 1994;8 (4):839-856.

10. Buskila D, Sarzi-Puttini P. Biology and therapy of fibromyalgia. Genetic aspects of fibromyalgia syndrome. Arthritis Res Ther. 2006;8(5):218. doi:10.1186/ar2005

11. Arnold LM, Clauw DJ, Dunegan LJ, Turk DC. A framework for fibromyalgia management for primary care providers. Mayo Clin Proc. 2012;87(5):488-496. doi:10.1016/j.mayocp.2012.02.010

12. Roizenblatt S, Neto NS, Tufik S. Sleep disorders and fibromyalgia. Curr Pain Headache Rep. 2011;15(5):347-357. doi:10.1007/s11916-0110213-3

13. Shah MA, Feinberg S, Krishnan E. Sleep-disordered breathing among women with fibromyalgia syndrome. J Clin Rheumatol. 2006;12(6):277-281. doi:10.1097/01.rhu.0000249771.97221.36

14. Wiegand L, Zwillich CW. Obstructive sleep apnea. Dis Mon. 1994;40 (4):197-252.

15. Greenberg-Dotan S, Reuveni H, Simon-Tuval T, Oksenberg A, Tarasiuk A. Gender differences in morbidity and health care utilization among adult obstructive sleep apnea patients. Sleep. 2007;30 (9):1173-1180.

16. Tarasiuk A, Greenberg-Dotan S, Simon-Tuval T, Oksenberg A, Reuveni $\mathrm{H}$. The effect of obstructive sleep apnea on morbidity and health care utilization of middle-aged and older adults. $J \mathrm{Am}$ Geriatr Soc. 2008;56(2):247-254. doi:10.1111/j.1532-5415. 2007.01544.x

17. Finan PH, Goodin, BR, Smith, MT. The association of sleep and pain: an update and a path forward. J Pain. 2013;14(12):1539-1552. doi:10.1016/j.jpain.2013.06.004

18. Aytekin E, Demir SE, Komut EA, et al. Chronic widespread musculoskeletal pain in patients with obstructive sleep apnea syndrome and the relationship between sleep disorder and pain level, quality of life, and disability. J Phys Ther Sci. 2015;27(9):2951-2954. doi:10.1589/ jpts.27.2951

19. May KP, West SG, Baker MR, Everett DW. Sleep apnea in male patients with the fibromyalgia syndrome. Am J Med. 1993;94 (5):505-508.

20. Cunningham JL, Evans MM, King SM, Gehin JM, Loukianova LL. Opioid tapering in fibromyalgia patients: experience from an interdisciplinary pain rehabilitation program. Pain Med. 2016;17:1676-1685. doi:10.1093/pm/pnv079

21. Fitzcharles MA, Ste-Marie PA, Gamsa A, Ware MA, Shir Y. Opioid use, misuse, and abuse in patients labeled as fibromyalgia. Am J Med. 2011;124(10):955-960. doi:10.1016/j. amjmed.2011.05.031

22. Rainville P. Brain mechanisms of pain affect and pain modulation. Curr Opin Neurobiol. 2002;12(2):195-204.

23. Roehrs T, Hyde M, Blaisdell B, Greenwald M, Roth T. Sleep loss and REM sleep loss are hyperalgesic. Sleep. 2006;29(2):145-151.

24. Rosenfeld VW, Rutledge DN, Stern JM. Polysomnography with quantitative EEG in patients with and without fibromyalgia. $J \quad$ Clin Neurophysiol. 2015;32(2):164-170. doi:10.1097/ WNP.0000000000000134 
25. Marvisi M, Balzarini L, Mancini C, Ramponi S, Marvisi C. Fibromyalgia is frequent in obstructive sleep apnea and responds to CPAP therapy. Eur J Intern Med. 2015;26:e49-e50. doi:10.1016/j. ejim.2015.06.010

26. Meresh E, Rao M, Ghattas A, Shah K. Polysomnographic findings in fibromyalgia: a retrospective chart review. Fibrom Open Access. 2017;2(2):126.

27. Alvarez Lario B, Teran J, Alonso JL, Alegre J, Arroyo I, Viejo JL. Lack of association between fibromyalgia and sleep apnoea syndrome. Ann Rheum Dis. 1992;51(1):108-111.

28. Plantamura A1, Steinbauer J, Eisinger J. Sleep apnea and fibromyalgia: the absence of correlation does not indicate an exclusive central hypothesis. Rev Med Interne. 1995;16(9):662-665. Article in French.

29. Okifuji A, Bradshaw DH, Olson C. Evaluating obesity in fibromyalgia: neuroendocrine biomarkers, symptoms, and functions. Clin Rheumatol. 2009;28:475-478. doi:10.1007/s10067-009-1094-2

30. Wolfe F, Clauw DJ, Fitzcharles MA, et al. The American College of Rheumatology preliminary diagnostic criteria for fibromyalgia and measurement of symptom severity. Arthritis Care Res. 2010;62:600-610. doi:10.1002/acr.20140
31. Choy EH. The role of sleep in pain and fibromyalgia. Nat Rev Rheumatol. 2015;11:513-520. doi:10.1038/nrrheum.2015.56

32. Roizenblatt S, Moldofsky H, Benedito-Silva AA, Tufik S. Alpha sleep characteristics in fibromyalgia. Arthritis Rheum. 2001;44:222-230. doi:10.1002/1529-0131(200101)44:1<222::AIDANR29>3.0.CO;2-K

33. Affleck G, Urrows S, Tennen H, Higgins P, Abeles M. Sequential daily relations of sleep, pain intensity, and attention to pain among women with fibromyalgia. Pain. 1996;68:363-368.

34. Aargün MY, Tekeolu I, Güne A, et al. Sleep quality and pain threshold in patients with fibromyalgia. Compr Psychiatry. 1999;40:226-228.

35. Scharf MB, Baumann M, Berkowitz DV. The effects of sodium oxybate on clinical symptoms and sleep patterns in patients with fibromyalgia. J Rheumatol. 2003;30:1070-1074.

36. Meresh E, Birch S, Owens JH, et al. A 5 year single-center retrospective analysis of co-morbidity of obstructive sleep apnea in patients with fibromyalgia. Presented as Poster, Academy of Psychosomatic Medicine Meeting; November 9; 2017; Palms Spring, CA. Poster nu: 044 .

\section{Publish your work in this journal}

Open Access Rheumatology Research and Reviews is an international, peer-reviewed, open access journal publishing original research, reports, editorials, reviews and commentaries on all aspects of clinical and experimental rheumatology in the clinic and laboratory including the following topics: Pathology, pathophysiology of rheumatological diseases; Investigation, treatment and management of rheumatological diseases; Clinical trials and novel pharmacological approaches for the treatment of rheumatological disorders. The manuscript management system is completely online and includes a very quick and fair peer-review system, which is all easy to use. Visit http://www.dovepress.com/testimonials.php to read real quotes from published authors. 